\title{
Strategies for Diabetes Management: Using Newer Oral Combination Therapies Early in the Disease
}

Joel Zonszein · Per-Henrik Groop

Received: August 19, 2016 / Published online: October 31, 2016

(C) The Author(s) 2016. This article is published with open access at Springerlink.com

\begin{abstract}
Introduction: The duration of uncontrolled type 2 diabetes mellitus (T2DM) can adversely impact small and large vessels, eventually leading to microvascular and macrovascular complications. Failure of therapeutic lifestyle changes, monotherapy, and clinical inertia contribute to persistent hyperglycemia and disease progression. The aim was to review the complex pathophysiology of type 2 diabetes and how different oral agents can be used
\end{abstract}

Enhanced Content To view enhanced content for this article go to http://www.medengine.com/Redeem/ 0217F060488512AE.

\section{J. Zonszein (ه)}

Montefiore Medical Center, University Hospital for Albert Einstein College of Medicine, Bronx, NY, USA e-mail: joel.zonszein@einstein.yu.edu

\section{P.-H. Groop}

Abdominal Center Nephrology, University of Helsinki and Helsinki University Hospital, Helsinki, Finland

P.-H. Groop

Folkhälsan Institute of Genetics, Folkhälsan

Research Center, Biomedicum Helsinki, Helsinki,

Finland

P.-H. Groop

Baker IDI Heart \& Diabetes Institute, Melbourne, Australia effectively as first-line therapy in combination with metformin, as well as in patients not achieving glycemic goals with metformin therapy.

Methods: For this review, a non-systematic literature search of PubMed, NCBI, and Google Scholar was conducted.

Results: New oral agents have made it possible to improve glycemic control to near-normal levels with a low risk of hypoglycemia and without weight gain, and sometimes with weight loss. Early combination therapy is effective and has been shown to have a favorable legacy effect. A number of agents are available in a single-pill combination (SPC) that provides fewer pills and better adherence. Compared with adding a sulfonylurea, still the most common oral combination used, empagliflozin has been shown to decrease cardiovascular $(\mathrm{CV})$ events in a dedicated $\mathrm{CV}$ outcome study, and pioglitazone has been effective in reducing the risk of secondary $\mathrm{CV}$ endpoints, whereas sulfonylureas have been associated with an increased risk of CV disease. In those failing metformin, triple oral therapy by adding a non-metformin SPC such as empagliflozin/linagliptin or pioglitazone/ 
alogliptin is a good option for reducing glycated hemoglobin (HbA1c) without significant hypoglycemia.

Conclusion: Clinicians have a comprehensive armamentarium of medications to treat patients with T2DM. Clinical evidence has shown that dual or triple oral combination therapy is effective for glycemic control, and early treatment is effective in getting patients to goal more quickly. Use of SPCs is an option for double or triple oral combination therapy and may result in better adherence.

Keywords: DPP-4 inhibitors; Early combination therapy; Hyperglycemia; Hypoglycemia; Oral glucose-lowering agents; SGLT2 inhibitors; Single-pill combination; Type 2 diabetes mellitus

\section{INTRODUCTION}

Over the last several decades, the diabetes landscape has been transformed by an improved understanding of its pathophysiology and the development of an array of antihyperglycemic medications [1]. Yet, diabetes remains a pervasive disease with immense public health consequences and increasing prevalence of type 2 diabetes mellitus (T2DM) in adults [2]. Despite the number of treatment options, hyperglycemia is still often poorly controlled [3], chiefly reflecting the limitations inherent in treatment options for T2DM and clinical inertia. Lifestyle changes such as diet or exercise are insufficient, and the efficacy of pharmacologic agents is rarely sustained over time and may be limited by side effects. After prescribing therapeutic lifestyle changes, there may be delays in initiating monotherapy, often metformin, and physicians may wait long periods of time (even years) before adding additional therapy [4]. This step-up approach is conducive to treatment failure; evidence from monotherapy studies shows that long-term glycemic control is often not durable $[5,6]$. Several studies have stressed the importance of early treatment, not only to prevent small vessel disease complications, but to prevent cardiovascular (CV) events years after the completion of the trial (a result of the legacy effect) as well [7-9].

The current therapeutic landscape also results from caution based on potential adverse events with available glucose-lowering agents [4]. For example, insulins and sulfonylureas (SUs) are associated with weight gain and hypoglycemia [1], the latter being of particular concern in the elderly [10]. The management of T2DM may be facilitated with single-pill combinations (SPC) by enabling patients to take fewer pills per day, which may lead to improved patient adherence [11]. Many combinations include metformin and can be used early in the disease. Two other SPCs, pioglitazone/alogliptin and empagliflozin/ linagliptin, have shown good glucose-lowering efficacy when added to metformin $[12,13]$.

It is important to choose agents that treat the patient as a whole, not just their hyperglycemia. For example, individuals with T2DM are at high risk of $\mathrm{CV}$ disease and need aggressive therapy that includes the management of concomitant $\mathrm{CV}$ risk factors such as obesity, hypertension, and dyslipidemia [14]. In addition, patients with T2DM and chronic kidney disease (CKD) are also at an increased risk of severe hypoglycemia [15] and present a treatment challenge. Metformin is not recommended for use in patients with an estimated glomerular filtration rate (eGFR) less than $45 \mathrm{~mL} / \mathrm{min} /$ $1.73^{2}$; however, metformin may be used safely in patients with mild impairment in kidney 
function and with proper monitoring in patients with moderate impairment in kidney function [16]. As the number of newly diagnosed patients with T2DM increases and patients live longer, CKD needs to be a consideration when choosing antihyperglycemic agents. In the recently published long-term follow-up to the Steno-2 trial of patients with T2DM and microalbuminuria, more intensified, multifactorial, target-driven treatment resulted in an almost 8-year longer survival with fewer CV complications [17]. Thus, a one-size-fits-all approach to treat hyperglycemia is insufficient and a patient-centered approach is necessary. Herein, we describe the rationale for early combination therapy, review the clinical efficacy and safety data for the empagliflozin/ linagliptin SPC, and discuss how SPC therapy can be used in a personalized approach. This review discusses only oral agents as they are more commonly used early in the disease. Of the nine classes of oral medications listed in Table 1, this paper focuses on the newer classes, dipeptidyl peptidase 4 (DPP-4) inhibitors and sodium glucose cotransporter 2 (SGLT-2) inhibitors, available in the USA, as well as the older SUs and thiazolidinediones (TZDs), agents that are commonly prescribed when metformin fails.

\section{REVIEW METHODS}

For this narrative review, a non-systematic literature search was conducted on various databases, including PubMed, NCBI, and Google Scholar. The search terms included type 2 diabetes, early treatment with oral agents such as linagliptin, empagliflozin, metformin, DPP-4 inhibitors, and fixed-dose combination with linagliptin and empagliflozin. Relevant references were identified after screening the titles, and results were then revised qualitatively on the basis of treatment initiation time and use of combination or fixed-dose therapy. Relevant clinical trials evaluating early combination therapy in patients with T2DM were identified on ClinicalTrials.gov. Other sources included drug manufacturers' websites and references known to the author.

\section{Compliance with Ethics Guidelines}

This article is based on previously conducted studies and does not involve any new studies of human or animal subjects performed by any of the authors.

\section{PATHOPHYSIOLOGY}

T2DM is a complex disease with multiple pathophysiologic components (Fig. 1). Elevated blood glucose results from insufficient insulin production and insulin resistance, as well as a closely intertwined dysfunction of many other metabolic and hormonal pathways [18]. Impaired $\beta$ cell function and impaired insulin secretion are hallmarks of T2DM. In addition, pancreatic $\alpha$ cells secrete inappropriately high amounts of glucagon in spite of hyperglycemia and hyperinsulinemia, the two major factors that decrease glucagon secretion and endogenous glucose production. As a result, inappropriate endogenous glucose production leads to fasting hyperglycemia and also contributes to postprandial hyperglycemia.

T2DM has evolved into a disorder that now affects a younger population afflicted with central obesity and abnormal adipocyte function [19]. In addition, the gastrointestinal 
Table 1 Classes of oral medications for glycemic management approved in the USA $[1,24]$

\begin{tabular}{|c|c|c|c|c|}
\hline Class & Compounds & Primary physiologic action & Hypoglycemia & Weight \\
\hline Biguanides & Metformin & $\downarrow$ Hepatic glucose production & Neutral & $\begin{array}{r}\text { Slight } \\
\text { loss }\end{array}$ \\
\hline Sulfonylureas & $\begin{array}{l}\text { Glyburide/glibenclamide } \\
\text { Glimepiride } \\
\text { Glipizide }\end{array}$ & $\uparrow$ Insulin secretion & Moderate/severe & Gain \\
\hline Meglitinides & $\begin{array}{l}\text { Repaglinide } \\
\text { Nateglinide }\end{array}$ & $\uparrow$ Insulin secretion & Mild & Gain \\
\hline Thiazolidinediones & $\begin{array}{l}\text { Pioglitazone } \\
\text { Rosiglitazone }\end{array}$ & $\uparrow$ Insulin sensitivity & Neutral & Gain \\
\hline $\begin{array}{l}\alpha \text {-Glucosidase } \\
\text { inhibitors }\end{array}$ & $\begin{array}{l}\text { Acarbose } \\
\text { Miglitol }\end{array}$ & Slows carbohydrate digestion/absorption & Neutral & Neutral \\
\hline DPP-4 inhibitors & $\begin{array}{l}\text { Alogliptin } \\
\text { Linagliptin } \\
\text { Sitagliptin } \\
\text { Saxagliptin }\end{array}$ & $\begin{array}{l}\uparrow \text { Insulin secretion (glucose-dependent) } \\
\downarrow \text { Glucagon secretion (glucose-dependent) }\end{array}$ & Neutral & Neutral \\
\hline $\begin{array}{l}\text { Bile acid } \\
\text { sequestrants }\end{array}$ & Colesevelam & $\begin{array}{l}\downarrow \text { Hepatic glucose production (?) } \\
\uparrow \text { Incretin levels (?) }\end{array}$ & Neutral & Neutral \\
\hline $\begin{array}{l}\text { Dopamine-2 } \\
\text { agonists }\end{array}$ & $\begin{array}{l}\text { Bromocriptine (quick } \\
\text { release) }\end{array}$ & $\begin{array}{l}\text { Modulates hypothalamic regulation of } \\
\text { metabolism } \\
\uparrow \text { Insulin sensitivity }\end{array}$ & Neutral & Neutral \\
\hline SGLT2 inhibitors & $\begin{array}{l}\text { Canagliflozin } \\
\text { Dapagliflozin } \\
\text { Empagliflozin }\end{array}$ & $\begin{array}{l}\text { Inhibit glucose reabsorption by the kidney } \\
\uparrow \text { Glucosuria }\end{array}$ & Neutral & Loss \\
\hline
\end{tabular}

$D P P-4$ dipeptidyl peptidase-4, SGLT2 sodium glucose cotransporter 2

tract exhibits abnormal secretion of incretin hormones, glucagon-like peptide 1 (GLP-1) and glucose-dependent insulinotropic polypeptide $[18,20]$. These two hormones account for $90 \%$ of the incretin effect, which plays a pivotal role in maintaining normal glucose homeostasis. The kidneys also play a crucial role in glucose homeostasis by releasing glucose into the circulation via gluconeogenesis, particularly during fasting, and reabsorbing all of the filtered glucose [21], both of which are adaptive mechanisms that ensure sufficient energy is available during fasting periods. The transport protein, SGLT2, is a low-affinity, high-capacity glucose transporter that reabsorbs approximately $90 \%$ of filtered glucose, while the high-affinity, low-capacity SGLT1 transporter reabsorbs the remainder [22]. 


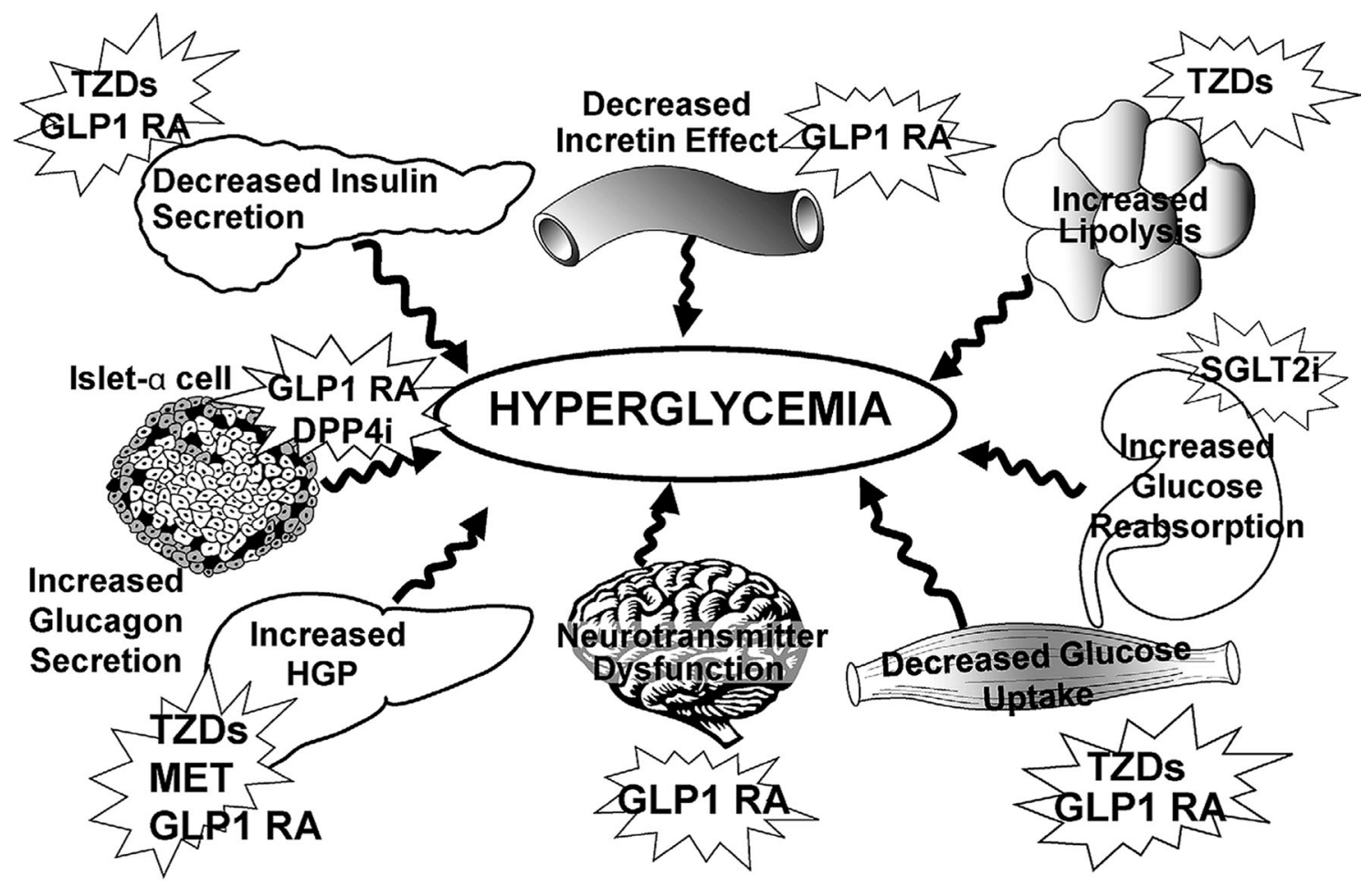

Fig. 1 Pathophysiologic abnormalities targeted by currently available antihyperglycemic medications. DPP4i dipeptidyl peptidase 4 inhibitor, GLPI RA glucagon-like peptide 1 receptor agonist, $H G P$ hepatic glucose production, MET metformin, SGLT2i sodium glucose cotransporter 2 inhibitor, $T Z D$ thiazolidinedione. "From the

A maladaptation takes place in individuals with diabetes with increased expression and activity of SGLT2 in the proximal tubule of the kidney. As a result, glucose reabsorption increases by as much as $20 \%$ in individuals with poorly controlled diabetes, contributing to hyperglycemia [22]. In T2DM and obesity, the central nervous system fuel feedback is affected by insulin and leptin resistance, further contributing to glycemic dysregulation. Individuals with obesity and T2DM are insulin and leptin resistant and display neurotransmitter dysfunction that alters the normal fuel feedback to the brain [23], making the central nervous system a critical player in triumvirate to the ominous octet: a new paradigm for the treatment of type 2 diabetes mellitus". American Diabetes Association, 2009. Copyright and all rights reserved. Material from this publication has been used with the permission of the American Diabetes Association

glucose dysregulation. In summary, complex and multiple pathophysiologic disturbances involving different organs and endocrine and neurologic pathways cause hyperglycemia, and therefore it is not surprising that a multitiered treatment approach is necessary.

\section{TREATMENT GUIDELINES AND APPROACHES}

Treatment guidelines developed by the American Diabetes Association (ADA) and the European Association for the Study of Diabetes (EASD), as well as by the American Association of Clinical Endocrinologists (AACE) and the 
American College of Endocrinology (ACE), recommend metformin as the first-choice pharmacotherapy if lifestyle changes, such as diet and exercise, fail to achieve glycated hemoglobin (HbA1c) goals within 3 months $[1,24]$. Metformin does not cause significant hypoglycemia, is weight neutral, inexpensive, and has a long-standing evidence base for efficacy and safety [1]; it may even reduce the risk of $\mathrm{CV}$ events [7]. On the basis of the Diabetes Prevention Program study, metformin is also recommended for individuals with prediabetes, particularly those with a body mass index greater than $35 \mathrm{~kg} / \mathrm{m}^{2}$, aged less than 60 years, and women with previous gestational diabetes $[25,26]$. If metformin is contraindicated (e.g., because of decreased renal function) or not tolerated, the AACE/ACE guidelines suggest the use of one of the newer agents, such as a GLP-1 receptor agonist, SGLT2 inhibitor, or DPP-4 inhibitor, over older agents ( $\alpha$-glucosidase inhibitors, TZDs, and SUs) [24]. The ADA/EASD Position Statement does not prioritize treatments and instead emphasizes patient preference and individualized treatment [1]. Individuals with T2DM benefit from learning about managing their disease, adopting a healthier lifestyle, and understanding the pros and cons of their medications. Well-structured education, such as diabetes self-management education, should aim to support informed decision-making, problem-solving, and active collaboration with the health care team to improve clinical outcomes, health status, and quality of life in a cost-effective manner [27, 28]. Monitoring glycemic goals via determination of HbA1c levels and self-monitoring of blood glucose (SMBG) varies according to the individual and his or her treatment [1].

\section{DPP-4 Inhibitors}

DPP-4 inhibitors are gastrointestinal peptides that enhance secretion of insulin from pancreatic $\beta$ cells and suppress glucagon release from pancreatic $\alpha$ cells in a glucose-dependent manner [29]. DPP-4 inhibitors have a low risk of hypoglycemia, are weight neutral, have been shown to improve $\beta$ cell function in animal and in vitro studies $[30,31]$, and can exert several favorable effects on the CV system, including improved ventricular function [32]. Currently, four DPP-4 inhibitors are approved in the USA for the treatment of hyperglycemia alone or in combination with other oral agents and insulin: alogliptin, linagliptin, sitagliptin, and saxagliptin (Table 2). In clinical trials, DPP-4 inhibitor monotherapy has been shown to improve glycemic control with mean reductions in $\mathrm{HbA} 1 \mathrm{c}$ in the range of $0.6-1.1 \%$ [33]. When used in patients with moderate or severe CKD, alogliptin, saxagliptin, and sitagliptin require a lower dose [34]. Linagliptin, the only DPP-4 inhibitor primarily excreted via the hepatic route, does not require any dose adjustment. All DPP-4 inhibitors are well tolerated, but have been associated with an increased frequency of stuffy nose or cough [35] and some cases of severe and disabling arthralgia have been reported more recently [36]. Reports of pancreatitis and pancreatic cancer with the use of incretinomimetics are still under investigation [37].

\section{SGLT2 Inhibitors}

SGLT2 inhibitors exert their effects via the kidney and their mechanism of action involves inhibiting the SGLT2 protein in the 


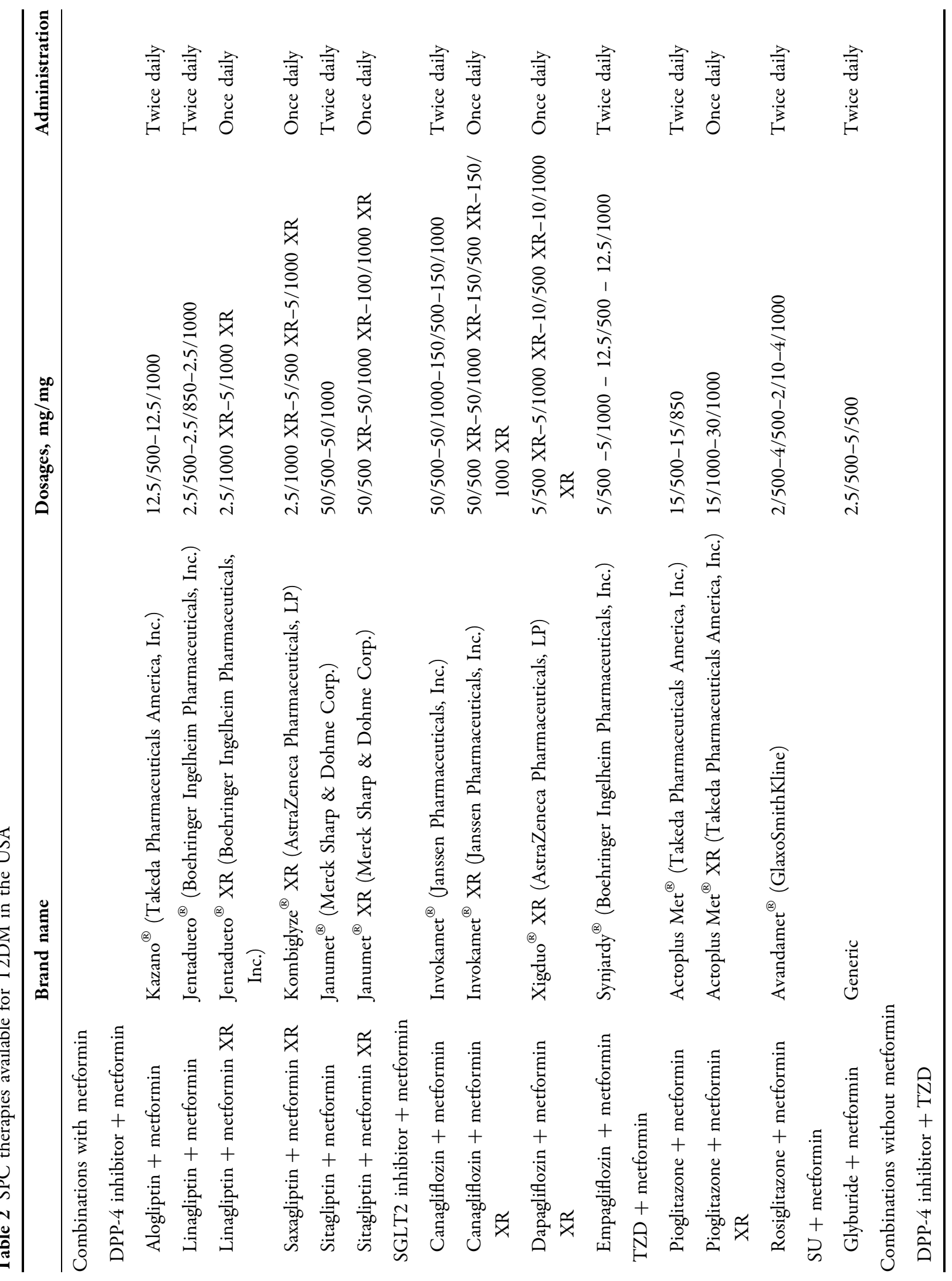




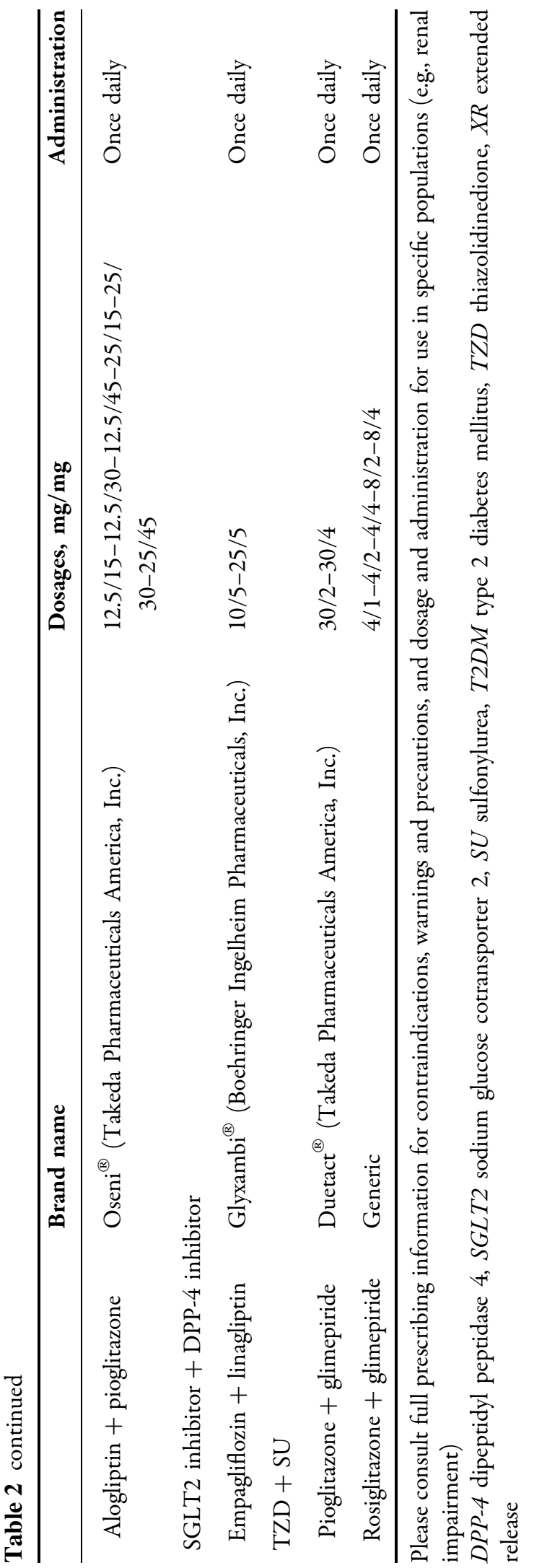

proximal nephron, thereby reducing the inappropriately increased glucose reabsorption found in T2DM and increasing urinary glucose excretion [38]. SGLT2 inhibitors have proven to be effective not only in improving glycemic management but also in decreasing weight and reducing systolic blood pressure (BP), with a low risk of hypoglycemia, except when used with insulin or SUs [38]. They provide significant reductions in $\mathrm{HbA1c}$ versus placebo and are similarly efficacious when compared with most standard oral agents in head-to-head trials [39]. Because this action is independent of insulin, SGLT2 inhibitors may be used at any stage of T2DM, even after insulin secretion has waned significantly [38].

The SGLT2 inhibitors lead to increased risk of genital mycotic infections, particularly in women. Urinary tract infections have also been reported to be more common in some patient groups, such as older patients, but the increase is less clear-cut than for genital infections [40]. Use of SGLT2 inhibitors also has the potential to cause hypotension and other hypovolemic events because of osmotic diuresis, particularly in older patients taking loop diuretics. In addition, trials have shown small increases in low-density lipoprotein cholesterol and, although these can be managed with appropriate treatment, the long-term consequences are unclear. Long-term trials to establish $\mathrm{CV}$ safety are still ongoing for canagliflozin and dapagliflozin [41]. Results from the EMPA-REG OUTCOME ${ }^{\circledR}$ trial showed a significant CV risk reduction [42], decreased $\mathrm{CV}$ and overall mortality, slower progression of kidney disease, and lower rates of clinically relevant renal events in patients with T2DM and $\mathrm{CV}$ risk factors who were treated with empagliflozin versus placebo in addition to standard of care [43] (see "CV Risk" section). 
Post-marketing reports of ketoacidosis have emerged after the approval of SGLT2 inhibitors, with a number of cases reporting minimal elevation of blood sugar (i.e., euglycemic ketoacidosis) [44]. The US Food and Drug Administration (FDA) has subsequently issued a warning alerting health care practitioners and patients to the signs and symptoms of ketoacidosis [45].

\section{Combination Therapy}

Current guidelines recommend combination therapy in patients with elevated HbA1c levels at diagnosis (ADA/EASD $>9.0 \%$; AACE/ $\mathrm{ACE} \geq 7.5 \%$ ) or after 3 months of monotherapy if HbA1c goals are not achieved [1, 24]. To address the lack of long-term studies assessing the efficacy and safety of initial combination therapy, the US National Institutes of Health has sponsored the Glycemia Reduction Approaches in Diabetes: A Comparative Effectiveness (GRADE) study [46]. The trial does not compare older combinations, such as TZDs, or newer agents, such as the SGLT2 inhibitors, and is limited to comparing the combination of metformin with DPP-4 inhibitors, GLP-1 receptor agonists, insulin, or SUs. Until the GRADE trial is completed (estimated 2020), only two randomized, controlled, long-term studies (both 5 years) are available. First, the Bypass Angioplasty Revascularization Investigation 2 Diabetes (BARI 2D) study compared two different strategies, insulin secretagogues (mainly insulin and SUs) versus insulin sensitizers (mainly metformin and rosiglitazone). The study showed that the insulin sensitizer strategy not only achieved better glycemic control but was also associated with less hypoglycemia and less weight gain [47]. The second trial, Rosiglitazone Evaluated for
Cardiovascular Outcomes and Regulation of Glycaemia in Diabetes (RECORD), compared metformin plus SU with metformin plus rosiglitazone, and also found better glycemic control with the combination of rosiglitazone and metformin [48]. Since these are the only two long-term randomized clinical trials available, treatment decisions should be patient-centered and include considerations such as efficacy, cost, potential side effects, weight, comorbidities, hypoglycemia risk, and patient preferences [25].

Although many shorter-term trials have compared dual therapy versus metformin monotherapy, few long-term, head-to-head studies have directly compared drugs as add-on therapy. A comparative effectiveness meta-analysis suggests that, overall, each new class of non-insulin agents added to initial therapy lowers HbA1c levels by approximately $1 \%$ [49]. These differences may be true in clinical trials, however, in day-to-day practice tremendous variability occurs among patients' responses to medications.

\section{RISK}

\section{Intensive Glucose Lowering}

$\mathrm{CV}$ disease is the major cause of morbidity and premature mortality and an important contributor to the direct and indirect costs of diabetes [50]. Benefits can be seen when multiple risk factors (e.g., BP, weight, smoking cessation) are addressed globally [51, 52]. Long-term clinical trials have also shown that aggressive glycemic treatment benefits CV outcomes years after the studies have been completed [7-9, 52]. These effects have been clearly demonstrated in patients with type 1 diabetes mellitus (T1DM) in the Diabetes Control and Complications Trial/ 
Epidemiology of Diabetes Interventions and Complications study (DCCT/EDIC) [53]. This was also shown in patients with T2DM in the UK Prospective Diabetes Study (UKPDS) [7], and more recently in the long-term follow-up of the Veterans Affairs Diabetes Trial (VADT) in which $\mathrm{CV}$ disease improvement was found 10 years after the study end [8], the legacy effect [7]. Although the Action to Control Cardiovascular Risk in Diabetes (ACCORD) study found that intensive therapy (targeting $\mathrm{HbA} 1 \mathrm{c}<6.0 \%$ ) in patients with T2DM increased mortality compared with standard therapy (targeting HbA1c 7.0-7.9\%) [54], the VADT and the Action in Diabetes and Vascular Disease (ADVANCE) trials showed that intensive glucose control did not increase mortality $[55,56]$. VADT showed a reduction in $\mathrm{CV}$ event rates years after the study was completed (median follow-up, 5.6 years) [8]. However, interventions at a later disease stage, such as intensive treatment in those with heart and kidney disease, can also produce a legacy effect after aggressive multifactorial treatment initiation. A recent follow-up to the Steno-2 trial, following patients for a mean of 21.2 years after 7.8 years of intensified multifactorial treatment in patients with T2DM and microalbuminuria, demonstrated a median gain of 7.9 life-years [17].

When metformin is not indicated or tolerated, including in treatment-naïve individuals, the empagliflozin/linagliptin SPC can be a good alternative. Although the addition of an SU is the most common step after metformin fails, these agents have been associated with hypoglycemia, sometimes requiring hospitalizations, particularly in the elderly [10] and in those with polypharmacy [57]. Observational cohort trials have also shown a disadvantage of SUs in general $[58,59]$, and when compared to DPP-4 inhibitors [60, 61].
Several CV outcomes trials have compared DPP-4 inhibitors with placebo or other agents in addition to the usual standard of care for glycemic control and CV risk factors [62-64]. In the Saxagliptin Assessment of Vascular Outcomes Recorded in Patients with Diabetes Mellitus-Thrombolysis in Myocardial Infarction (SAVOR-TIMI) 53 trial, which compared saxagliptin versus placebo in T2DM patients with either a history of established CV events or at high risk of $\mathrm{CV}$ events $(N=16,492)$ over a median of 2.1 years, the rates of the composite primary endpoint [CV death, nonfatal myocardial infarction (MI), or ischemic stroke] were similar between the treatment groups [hazard ratio (HR), 1.00; 95\% confidence interval $\quad(\mathrm{CI}), \quad 0.89-1.12 ; \quad P<0.001 \quad$ for non-inferiority; $P=0.99$ for superiority] [62]. However, saxagliptin showed a higher rate of hospitalization due to heart failure (3.5\%) relative to placebo $(2.8 \%$; HR, $1.27 ; 95 \% \mathrm{CI}$, 1.07-1.51; $P=0.007$ ) [62]. In the Examination of Cardiovascular Outcomes with Alogliptin versus Standard of Care (EXAMINE) trial, which investigated alogliptin versus placebo in patients with acute coronary syndrome over a median of 1.5 years, alogliptin was non-inferior to placebo for the primary composite endpoint (CV death, nonfatal MI, or nonfatal stroke): HR, 0.96; upper boundary of the one-sided repeated CI, $1.16 ; P<0.001$ for non-inferiority; $P=0.32$ for superiority [63]. Moreover, in a post hoc analysis, the first hospitalization due to heart failure occurred at similar rates in both treatment groups (alogliptin, 3.1\%, placebo, 2.9\%; HR, 1.07; 95\% CI, 0.79-1.46; $P=0.657$ ) [64]. The larger $(N=14,671)$ and longer (median follow-up, 3.0 years) Trial Evaluating Cardiovascular Outcomes with Sitagliptin (TECOS) trial evaluated sitagliptin versus placebo on top of usual care in patients at least 50 years of age with T2DM and established 
CV disease [65]. The results reassuringly demonstrated no increased risk versus placebo for the primary composite $\mathrm{CV}$ endpoint of $\mathrm{CV}$ death, nonfatal MI, nonfatal stroke, or hospitalization for unstable angina (alogliptin, 9.6\%, placebo, 9.6\%; HR, 0.98; 95\% CI, 0.88-1.09; $P<0.001$ for non-inferiority in the per-protocol population; $P=0.65$ for superiority) and no increase in hospitalization for heart failure [HR in the intent-to-treat analysis: 1.00 (95\% CI, 0.83-1.20); $P=0.98$ ] [65].

\section{Outcomes Trials with SGLT2 Inhibitors}

Ongoing clinical trials assessing the impact of the SGLT2 inhibitors dapagliflozin and canagliflozin in patients with T2DM at high risk of CV complications include Dapagliflozin Effect on CardiovascuLAR Events (DECLARE-TIMI 58) [41] and CANagliflozin cardioVascular Assessment Study (CANVAS) $[66,67]$. For empagliflozin, the recently completed EMPA-REG OUTCOME ${ }^{\circledR}$ trial is the first dedicated $\mathrm{CV}$ outcome study to demonstrate that a glucose-lowering agent can improve CV endpoints and lower CV mortality as well as all-cause mortality in patients with T2DM at high risk of CV events [42]. It evaluated the effects of empagliflozin (10 or $25 \mathrm{mg}$ once daily versus placebo) on top of standard of care on $\mathrm{CV}$ outcomes in 7020 patients with T2DM at high risk of $\mathrm{CV}$ disease. The primary outcome was a composite of death from CV causes, nonfatal MI, or nonfatal stroke (3-point major adverse cardiovascular events or MACE) and was significantly reduced with empagliflozin (HR, 0.86, 95\% CI, $0.74-0.99 ; \quad P<0.001$ for non-inferiority and $P=0.04$ for superiority). Empagliflozin resulted in significantly lower rates of death from CV causes (HR, 0.62; 95\% CI, $0.49-0.77 ; \quad P<0.001)$, hospitalization for heart failure (HR, 0.65; 95\% CI, 0.50-0.85; $P=0.002)$, and death from any cause (HR, 0.68; 95\% CI, 0.57-0.82; $P<0.001)$. Among patients receiving empagliflozin, there was an increased rate of genital infection but no increase in other adverse events.

\section{Outcomes Trials with TZDs}

The TZDs are among the most potent insulin-sensitizing drugs available. Their use in patients with T2DM has decreased mainly as a result of the adverse $\mathrm{CV}$ outcomes attributed to rosiglitazone [68]. Pioglitazone, the other agent in this class, may reduce the risk of CV events, including stroke [69]. The PROspective PioglitAzone Clinical Trial In macro-Vascular Events (PROactive) trial evaluated the addition of pioglitazone to current therapy in patients with T2DM and a history of macrovascular disease $(N=5238)$. Although the trial failed to meet its primary composite endpoint of death from any cause, nonfatal MI, stroke, acute coronary syndrome, leg amputation, coronary revascularization, or revascularization of the leg, a significant reduction in the composite secondary endpoint was observed (death from any cause, nonfatal MI, or nonfatal stroke: HR 0.84; 95\% CI, 0.72-0.98; $P=0.027$ ) [70]. In a follow-up analysis, the pioglitazone reduced rates of fatal or nonfatal stroke and the composite of $\mathrm{CV}$ death, nonfatal stroke, or MI among patients with a history of previous stroke [69]. More recently, pioglitazone was also found to lower the risk of stroke or MI in individuals without diabetes who had insulin resistance along with ischemic stroke or transient ischemic attacks [71]. Although pioglitazone has shown beneficial CV outcomes, other studies with the long-term use of TZDs, mainly rosiglitazone $[48,72]$, have shown no superiority. 


\section{SPC THERAPY}

Individuals with T2DM are often exposed to polypharmacy, not only because of the need for multiple antihyperglycemic agents but also because of additional medications for the treatment of $\mathrm{CV}$ risk factors, including hypertension, dyslipidemia, and other comorbidities [73]. In the Diabetes and Aging Study, which analyzed data from more than 46,000 patients with T2DM in the USA, the mean number of prescribed medications was 4.2 , with $14 \%$ of patients taking more than seven medications [74]. Similarly large numbers of medications were used by patients in the UKPDS 35 prospective observational study and the BARI 2D trials $[47,75]$. Given the substantial polypharmacy, strategies to improve adherence are welcome in T2DM. As such, treatment with an SPC can facilitate medication adherence, with the goal of improving health outcomes.

Using SPCs simplifies the treatment regimen by decreasing the number of pills and reducing the frequency of administration. Studies show that adherence is improved with administration of one tablet per day versus multiple tablets per day [76-81]. Greater improvements in glycemic control have also been shown with an SPC versus the same medications coadministered as separate pills [77]. However, data directly addressing the effects of antihyperglycemic SPCs with respect to health care costs are quite limited [82]. Some data suggest reduced health care utilization and costs with an SPC versus loose-pill regimens [11] —a paradox as many formularies penalize SPCs with higher prices. Prescribing an SPC limits dose flexibility, and thus many physicians prefer using them as a maintenance option rather than an initial therapy. However, the SPCs currently available for use in T2DM are formulated in a variety of dosage combinations [83] (Table 2). Modern antihyperglycemic SPCs are easy to tolerate, easy to prescribe, require little or no dose titration, are associated with a low risk of hypoglycemia, and therefore need less frequent blood glucose monitoring.

Efficacy is generally comparable between SPCs and separate-pill combination therapy [84]. Although randomized controlled studies of SPCs are limited, most studies demonstrate improved or equivalent efficacy of the SPCs compared with the monotherapies [83]. Pharmacokinetic studies have demonstrated bioequivalence for several SPCs with their corresponding loose-pill regimens, including those with metformin extended release (XR) [e.g., Actoplus Met $^{\circledR}$ XR $\quad$ (Takeda Pharmaceuticals America, Inc.), Kombiglyze ${ }^{\circledR}$ XR (AstraZeneca Pharmaceuticals, LP), and Janumet $^{\circledR}$ XR (Merck Sharp \& Dohme Corp.)] [83]. Metformin, the most commonly found agent in the SPC therapies currently available in the USA, is effective in reducing blood glucose levels, but some patients have difficulty tolerating this agent because of adverse gastrointestinal effects [85]. Despite these adverse effects, metformin remains the most commonly prescribed medication, both in monotherapy and combination [86]. SPCs are particularly useful when they can be taken once daily, and there are many fixed-dose combinations containing metformin XR (Table 2), which also improves gastrointestinal tolerability [83]. One pill a day facilitates adherence [76].

As with metformin, SUs have also been used extensively in SPC therapies, partly because they have been available for many years and partly because they are generic and thus relatively inexpensive. The initial SPC was a combination of metformin and an SU. It was followed by an SU combined with a TZD, now also available in a generic form (Table 2). These 
SPCs may be less frequently prescribed because they are associated with the disadvantages of SUs; namely, lack of glycemic durability, hypoglycemia, and weight gain [25]. The third type of SPC therapy contains neither metformin nor an SU; these agents can be added to metformin when metformin alone is no longer sufficient. There are only two such SPCs approved by the US FDA: pioglitazone/ alogliptin $\left[\right.$ Oseni ${ }^{\circledR}$ (Takeda Pharmaceuticals America, Inc.)] and empagliflozin/linagliptin [Glyxambi $^{\circledR} \quad$ (Boehringer Ingelheim Pharmaceuticals, Inc.)] [87]. The combination of dapagliflozin/saxagliptin was submitted for FDA review, and the FDA has asked for additional data.

\section{Empagliflozin/Linagliptin SPC}

When treatment with metformin alone is not sufficient, the empagliflozin/linagliptin SPC can provide better HbA1c reductions than empagliflozin or linagliptin alone. In a placebo-controlled study $(n=674), 61.8 \%$ and $57.8 \%$ of patients with baseline $\mathrm{HbA1c}$ of at least $7.0 \%$ achieved an HbA1c of less than 7.0\% at week 24 with empagliflozin $25 \mathrm{mg} /$ linagliptin $5 \mathrm{mg}$ and empagliflozin $10 \mathrm{mg} /$ linagliptin $5 \mathrm{mg}$, respectively, versus $28.0-36.1 \%$ of patients who were using any of the three agents alone [13]. Even greater $\mathrm{HbA1c}$ reductions were achieved in individuals with a baseline HbA1c of at least $8.5 \%$, and these improvements in glycemic control were associated with weight loss and reduced systolic BP [13].

The empagliflozin/linagliptin SPC may be a good alternative when metformin is not indicated or tolerated or in treatment-naïve individuals. In treatment-naïve patients with T2DM and moderate hyperglycemia $(n=677$; mean HbA1c, $8.0 \%)$, the proportion who achieved HbA1c levels less than $7.0 \%$ at
24 weeks was higher with empagliflozin $25 \mathrm{mg} /$ linagliptin $\quad 5 \mathrm{mg} \quad(55.4 \%) \quad$ and empagliflozin $10 \mathrm{mg} /$ linagliptin $5 \mathrm{mg}$ (62.3\%) versus empagliflozin alone $(25 \mathrm{mg}, 41.5 \%$; $10 \mathrm{mg}, 38.8 \%)$ or linagliptin alone (5 mg, $32.3 \%$ ) [88]. In this trial, however, the empagliflozin $25 \mathrm{mg} /$ linagliptin $5 \mathrm{mg}$ SPC was not significantly better than empagliflozin $25 \mathrm{mg}$ alone. When compared with linagliptin $5 \mathrm{mg}$ alone, both SPC doses significantly reduced HbA1c, suggesting that without metformin the glucose reduction is mostly driven by empagliflozin [88]. Body weight reductions with the SPCs were also similar to empagliflozin alone, as were systolic BP reductions from baseline $(2.1-2.5 \mathrm{mmHg})$ and a low incidence of hypoglycemia.

In both of these trials, events consistent with urinary tract infections occurred at comparable rates across all groups (10-16\%), and events consistent with genital infection were present in $2-8.5 \%$ of patients, mostly women. In summary, the empagliflozin/linagliptin SPC is well tolerated, may cause a modest weight loss with lower systolic BP, and has a low rate of hypoglycemia.

\section{Pioglitazone/Alogliptin SPC}

Another available SPC is pioglitazone plus alogliptin. In drug-naïve patients, the combination with pioglitazone $30 \mathrm{mg} /$ alogliptin $25 \mathrm{mg}$ resulted in greater reductions in HbA1c $(-1.7 \pm 0.1 \%$ from an $8.8 \%$ mean baseline) versus pioglitazone $30 \mathrm{mg}$ $(-1.2 \pm 0.1 \%, P<0.001)$ or alogliptin $25 \mathrm{mg}$ $(-1.0 \pm 0.1 \%, \quad P<0.001)$ alone [89]. When added to metformin, the pioglitazone/ alogliptin SPC was also well tolerated and effective [12]. When administered to individuals with $\mathrm{HbA1c} 7.5-10.0 \%$ receiving at least $1500 \mathrm{mg} /$ day of metformin, pioglitazone 
plus metformin (pooled group) achieved a mean $\mathrm{HbA1c}$ reduction from baseline of $0.9 \%$. In contrast, participants receiving triple therapy (alogliptin, pioglitazone, and metformin) achieved a mean HbA1c reduction of $1.4 \%$ $(P<0.001$ versus the pioglitazone plus metformin pooled group).

\section{CONCLUSIONS}

Antihyperglycemic SPCs have been developed in an effort to address the issues of adherence associated with combination pharmacotherapy for patients with T2DM, with the goal of optimizing clinical outcomes. Most SPCs contain metformin or an SU. On the basis of current guidelines, metformin is the preferred choice for one of the agents in combination therapy. The use of SUs is less desirable because of weight gain, hypoglycemia, and potential CV risks. When considering orally administered alternatives or additions to metformin therapy, agents with a low risk of hypoglycemia that provide weight neutrality or weight loss and have a proven CV safety profile are preferred.

In the USA, two non-metformin combinations are available, alogliptin/pioglitazone and linagliptin/ empagliflozin. Both combinations contain DPP-4 inhibitors, which are associated with weight neutrality. However, when used in combination, linagliptin/empagliflozin is associated with weight loss due to the SGLT2 component, and alogliptin/pioglitazone is associated with weight gain due to the TZD component. These combinations are associated with a low risk of hypoglycemia (except when used in conjunction with insulin or insulin secretagogues). Neither combination has been studied in a dedicated CV outcomes trial.
Several CV outcomes trials have been completed for the individual glucose-lowering agents. CV outcomes trials for sitagliptin, saxagliptin, and alogliptin have shown no increased risk of overall CV events. EMPA-REG OUTCOME is the only trial that has demonstrated that adding empagliflozin causes a reduction in major adverse $\mathrm{CV}$ events, all-cause mortality, CV mortality, and heart failure, as well as an improvement in renal outcomes, when compared to treatment placebo on top of the current recommended standard of care [42, 43]. In a post hoc analysis pioglitazone has also been found to have favorable $\mathrm{CV}$ outcomes when used for secondary intervention when compared to placebo [69, 70]. In summary, we now have different choices in the selection of oral agents available for management of hyperglycemia. While the treatment choice needs to be patient-centered, we now have medications that in addition to glycemic control also reduce $\mathrm{CV}$ outcomes.

Early diagnosis of T2DM and aggressive glycemic treatment may help preserve $\beta$ cell function. In addition, clinical studies suggest that aggressive and early glycemic therapy reduces complications, and the use of lifestyle changes together with initial combination therapy is recommended. Clinicians now have a choice of what to use initially with metformin, or what to add when metformin fails. Newer combinations are weight neutral or may provide weight loss. Adding an SPC may improve adherence by decreasing the number of pills needed. Finally, the cost of expensive newer medications must be measured along with the potential costs of complications associated with older medications. For example, sulfonylureas are associated with hypoglycemia, and medical interventions for 
hypoglycemia often require more monitoring and sometimes costly hospitalizations [90].

In managing diabetes, early diagnosis and treatment with better lifestyles and proper medications can normalize HbA1c without hypoglycemia and/or weight gain. The use of SPC therapy is recommended for better adherence, and a more aggressive early treatment should result in fewer complications and a better quality of life. Consideration is needed in every case to provide a patient-centered approach that treats the patient as a whole. This necessarily includes taking into account concomitant risk factors such as obesity, hypertension, dyslipidemia, and renal impairment, as well as addressing medication risk-benefit profiles and costs, when making treatment choices.

\section{ACKNOWLEDGEMENTS}

No funding or sponsorship was received for this study or publication of this article. Editorial support for this manuscript was provided by Linda Merkel, PhD, of Envision Scientific Solutions, which was contracted and funded by Boehringer Ingelheim Pharmaceuticals, Inc. (BIPI). BIPI was given the opportunity to review the manuscript for medical and scientific accuracy as well as intellectual property considerations. The authors retained complete and final authority of this manuscript. All named authors meet the International Committee of Medical Journal Editors (ICMJE) criteria for authorship for this manuscript, take responsibility for the integrity of the work as a whole, and have given final approval for the version to be published.

Disclosures. J Zonszein is a consultant or speaker for Novo Nordisk, Takeda
Pharmaceuticals North America, Inc, Sanofi, and Boehringer Ingelheim. P-H Groop Per-Henrik Groop has received lecture honoraria from AstraZeneca, Boehringer Ingelheim, Eli Lilly, Genzyme, MSD, Novartis, Novo Nordisk; has received investigator-initiated grants from Eli Lilly and Roche; and is a member of advisory boards for AbbVie, Boehringer Ingelheim, Cebix, Eli Lilly, Janssen, Medscape, MSD, Novartis, and Sanofi.

Compliance with Ethics Guidelines. This article is based on previously conducted studies and does not involve any new studies of human or animal subjects performed by any of the authors.

Open Access. This article is distributed under the terms of the Creative Commons Attribution-NonCommercial 4.0 International License (http://creativecommons.org/licenses/ by-nc/4.0/), which permits any noncommercial use, distribution, and reproduction in any medium, provided you give appropriate credit to the original author(s) and the source, provide a link to the Creative Commons license, and indicate if changes were made.

\section{REFERENCES}

1. Inzucchi SE, Bergenstal RM, Buse JB, et al. Management of hyperglycemia in type 2 diabetes, 2015: a patient-centered approach. Update to a position statement of the American Diabetes Association and the European Association for the Study of Diabetes. Diabetes Care. 2015;38(1):140-9.

2. Centers for Disease Control. Diabetes Report Card. 2014. http://www.cdc.gov/diabetes/pdfs/library/ diabetesreportcard2014.pdf. Accessed 25 Aug 2015.

3. Ali MK, Bullard KM, Saaddine JB, Cowie CC, Imperatore G, Gregg EW. Achievement of goals in U.S. diabetes care, 1999-2010. N Engl J Med. 2013;368(17):1613-24. 
4. Khunti K, Wolden ML, Thorsted BL, Andersen M, Davies MJ. Clinical inertia in people with type 2 diabetes: a retrospective cohort study of more than 80,000 people. Diabetes Care. 2013;36(11):3411-7.

5. Kahn SE, Haffner SM, Heise MA, et al. Glycemic durability of rosiglitazone, metformin, or glyburide monotherapy. N Engl J Med. 2006;355(23):2427-43.

6. Turner RC, Cull CA, Frighi V, Holman RR. Glycemic control with diet, sulfonylurea, metformin, or insulin in patients with type 2 diabetes mellitus: progressive requirement for multiple therapies (UKPDS 49). UK Prospective Diabetes Study (UKPDS) Group. JAMA. 1999;281(21):2005-12.

7. Holman RR, Paul SK, Bethel MA, Matthews DR, Neil HA. 10-year follow-up of intensive glucose control in type 2 diabetes. $\mathrm{N}$ Engl $\mathrm{J}$ Med. 2008;359(15):1577-89.

8. Hayward RA, Reaven PD, Wiitala WL, et al. Follow-up of glycemic control and cardiovascular outcomes in type 2 diabetes. $\mathrm{N}$ Engl J Med. 2015;372(23):2197-206.

9. Nathan DM, Cleary PA, Backlund JY, et al. Intensive diabetes treatment and cardiovascular disease in patients with type 1 diabetes. $\mathrm{N}$ Engl J Med. 2005;353(25):2643-53.

10. Lipska KJ, Ross JS, Wang Y, et al. National trends in US hospital admissions for hyperglycemia and hypoglycemia among Medicare beneficiaries, 1999 to 2011. JAMA Intern Med. 2014;174(7):1116-24.

11. Lokhandwala $\mathrm{T}$, Smith $\mathrm{N}$, Sternhufvud C, Sorstadius E, Lee WC, Mukherjee J. A retrospective study of persistence, adherence, and health economic outcomes of fixed-dose combination vs. loose-dose combination of oral anti-diabetes drugs. J Med Econ. 2016;19(3): 203-12.

12. DeFronzo RA, Burant CF, Fleck P, Wilson C, Mekki Q, Pratley RE. Efficacy and tolerability of the DPP-4 inhibitor alogliptin combined with pioglitazone, in metformin-treated patients with type 2 diabetes. J Clin Endocrinol Metab. 2012;97(5):1615-22.

13. DeFronzo RA, Lewin A, Patel S, et al. Combination of empagliflozin and linagliptin as second-line therapy in subjects with type 2 diabetes inadequately controlled on metformin. Diabetes Care. 2015;38(3):384-93.

14. Gaede P, Vedel P, Larsen N, Jensen GV, Parving HH, Pedersen O. Multifactorial intervention and cardiovascular disease in patients with type 2 diabetes. N Engl J Med. 2003;348(5):383-93.
15. National Kidney Foundation. K/DOQI Clinical practice guidelines for chronic kidney disease: evaluation, classification and stratification. 2002. https://www.kidney.org/sites/default/files/docs/ckd_ evaluation_classification_stratification.pdf. Accessed 25 Aug 2015.

16. US Food and Drug Administration. FDA Drug Safety Communication: FDA revises warnings regarding use of the diabetes medicine metformin in certain patients with reduced kidney function. http://www. fda.gov/Drugs/DrugSafety/ucm493244.htm Accessed 18 April 2016.

17. Gaede P, Oellgaard J, Carstensen B, et al. Years of life gained by multifactorial intervention in patients with type 2 diabetes mellitus and microalbuminuria: 21 years follow-up on the Steno-2 randomised trial. Diabetologia. 2016;59(11):2298-307.

18. DeFronzo RA. Banting Lecture. From the triumvirate to the ominous octet: a new paradigm for the treatment of type 2 diabetes mellitus. Diabetes. 2009;58(4):773-95.

19. Goyal A, Nimmakayala KR, Zonszein J. Is there a paradox in obesity? Cardiol Rev. 2014;22(4):163-70.

20. Nauck MA, Vardarli I, Deacon CF, Holst JJ, Meier JJ. Secretion of glucagon-like peptide-1 (GLP-1) in type 2 diabetes: what is up, what is down? Diabetologia. 2011;54(1):10-8.

21. Gerich JE. Role of the kidney in normal glucose homeostasis and in the hyperglycaemia of diabetes mellitus: therapeutic implications. Diabet Med. 2010;27(2):136-42.

22. DeFronzo RA, Davidson JA, Del Prato S. The role of the kidneys in glucose homeostasis: a new path towards normalizing glycaemia. Diabetes Obes Metab. 2012;14(1):5-14.

23. Schwartz MW, Seeley RJ, Tschop MH, et al. Cooperation between brain and islet in glucose homeostasis and diabetes. Nature. 2013;503(7474):59-66.

24. Garber AJ, Abrahamson MJ, Barzilay JI, et al. AACE/ ACE comprehensive diabetes management algorithm 2015. Endocr Pract. 2015;21(4):438-47.

25. American Diabetes Association. Standards of medical care in diabetes-2015. Diabetes Care. 2015;38(Suppl):S1-93.

26. Knowler WC, Barrett-Connor E, Fowler SE, et al. Reduction in the incidence of type 2 diabetes with lifestyle intervention or metformin. N Engl J Med. 2002;346(6):393-403. 
27. Haas L, Maryniuk M, Beck J, et al. National standards for diabetes self-management education and support. Diabetes Care. 2014;37(Suppl 1):S144-53.

28. Torres EA, Tiwari A, Movsas S, Carrasquillo I, Zonszein J. Underutilization of diabetes education: experience in an urban teaching hospital in the Bronx. J Diabetes Metab Syndr Disord. 2015;2:005.

29. Drucker DJ, Nauck MA. The incretin system: glucagon-like peptide-1 receptor agonists and dipeptidyl peptidase- 4 inhibitors in type 2 diabetes. Lancet. 2006;368(9548):1696-705.

30. Jurczyk A, Diiorio P, Brostowin D, et al. Improved function and proliferation of adult human beta cells engrafted in diabetic immunodeficient NOD-scid IL2rgamma(null) mice treated with alogliptin. Diabetes Metab Syndr Obes. 2013;6:493-9.

31. Shah P, Ardestani A, Dharmadhikari G, et al. The DPP-4 inhibitor linagliptin restores beta-cell function and survival in human isolated islets through GLP-1 stabilization. J Clin Endocrinol Metab. 2013;98(7):E1163-72.

32. Green JB. The dipeptidyl peptidase- 4 inhibitors in type 2 diabetes mellitus: cardiovascular safety. Postgrad Med. 2012;124(4):54-61.

33. Aroda VR, Henry RR, Han J, et al. Efficacy of GLP-1 receptor agonists and DPP-4 inhibitors: meta-analysis and systematic review. Clin Ther. 2012;34(6):1247-58, e22.

34. Scheen AJ. Pharmacokinetics and clinical use of incretin-based therapies in patients with chronic kidney disease and type 2 diabetes. Clin Pharmacokinet. 2015;54(1):1-21.

35. Karagiannis T, Paschos P, Paletas K, Matthews DR, Tsapas A. Dipeptidyl peptidase- 4 inhibitors for treatment of type 2 diabetes mellitus in the clinical setting: systematic review and meta-analysis. BMJ. 2012;344:e1369.

36. US Food and Drug Administration. FDA Drug Safety Communication: FDA warns that DPP-4 inhibitors for type 2 diabetes may cause severe joint pain. 2015. http://www.fda.gov/Drugs/DrugSafety/ ucm459579.htm. Accessed 28 Aug 2015.

37. Egan AG, Blind E, Dunder K, et al. Pancreatic safety of incretin-based drugs-FDA and EMA assessment. N Engl J Med. 2014;370(9):794-7.

38. Bays H. Sodium glucose co-transporter type 2 (SGLT2) inhibitors: targeting the kidney to improve glycemic control in diabetes mellitus. Diabetes Ther. 2013;4(2):195-220.
39. Scheen AJ. Pharmacodynamics, efficacy and safety of sodium-glucose co-transporter type 2 (SGLT2) inhibitors for the treatment of type 2 diabetes mellitus. Drugs. 2015;75(1):33-59.

40. Geerlings S, Fonseca V, Castro-Diaz D, List J, Parikh S. Genital and urinary tract infections in diabetes: impact of pharmacologically-induced glucosuria. Diabetes Res Clin Pract. 2014;103(3):373-81.

41. Ghosh RK, Bandyopadhyay D, Hajra A, Biswas M, Gupta A. Cardiovascular outcomes of sodium-glucose cotransporter 2 inhibitors: a comprehensive review of clinical and preclinical studies. Int J Cardiol. 2016;212:29-36.

42. Zinman B, Wanner C, Lachin JM, et al. Empagliflozin, cardiovascular outcomes, and mortality in type 2 diabetes. $\mathrm{N}$ Engl J Med. 2015;373(22):2117-28.

43. Wanner C, Inzucchi SE, Lachin JM, et al. Empagliflozin and progression of kidney disease in type 2 diabetes. N Engl J Med. 2016;375(4):323-34.

44. Rosenstock J, Ferrannini E. Euglycemic diabetic ketoacidosis: a predictable, detectable, and preventable safety concern with SGLT2 inhibitors. Diabetes Care. 2015;38(9):1638-42.

45. US Food and Drug Administration. FDA Drug Safety Communication: FDA warns that SGLT2 inhibitors for diabetes may result in a serious condition of too much acid in the blood. 2015. http://www.fda.gov/ Drugs/DrugSafety/ucm446845.htm. Accessed 13 July 2015.

46. Nathan DM, Buse JB, Kahn SE, et al. Rationale and design of the glycemia reduction approaches in diabetes: a comparative effectiveness study (GRADE). Diabetes Care. 2013;36(8):2254-61.

47. Frye RL, August P, Brooks MM, et al. A randomized trial of therapies for type 2 diabetes and coronary artery disease. N Engl J Med. 2009;360(24):2503-15.

48. Home PD, Pocock SJ, Beck-Nielsen $\mathrm{H}$, et al. Rosiglitazone evaluated for cardiovascular outcomes in oral agent combination therapy for type 2 diabetes (RECORD): a multicentre, randomised, open-label trial. Lancet. 2009;373(9681):2125-35.

49. Bennett WL, Maruthur NM, Singh S, et al. Comparative effectiveness and safety of medications for type 2 diabetes: an update including new drugs and 2-drug combinations. Ann Intern Med. 2011;154(9):602-13.

50. Mozaffarian D, Benjamin EJ, Go AS, et al. Heart disease and stroke statistics-2015 update: a report 
from the American Heart Association. Circulation. 2015;131(4):e29-322.

51. Buse JB, Ginsberg HN, Bakris GL, et al. Primary prevention of cardiovascular diseases in people with diabetes mellitus: a scientific statement from the American Heart Association and the American Diabetes Association. Diabetes Care. 2007;30(1):162-72.

52. Gaede P, Lund-Andersen H, Parving HH, Pedersen O. Effect of a multifactorial intervention on mortality in type 2 diabetes. $\mathrm{N}$ Engl J Med. 2008;358(6):580-91.

53. Lachin JM, Orchard TJ, Nathan DM. Update on cardiovascular outcomes at 30 years of the Diabetes Control and Complications Trial/Epidemiology of Diabetes Interventions and Complications study. Diabetes Care. 2014;37(1):39-43.

54. Gerstein HC, Miller ME, Byington RP, et al. Effects of intensive glucose lowering in type 2 diabetes. N Engl J Med. 2008;358(24):2545-59.

55. Duckworth W, Abraira C, Moritz T, et al. Glucose control and vascular complications in veterans with type 2 diabetes. N Engl J Med. 2009;360(2):129-39.

56. Patel A, MacMahon S, Chalmers J, et al. Intensive blood glucose control and vascular outcomes in patients with type 2 diabetes. $\mathrm{N}$ Engl J Med. 2008;358(24):2560-72.

57. Lipska KJ, Krumholz $H$, Soones $T$, Lee SJ. Polypharmacy in the aging patient: a review of glycemic control in older adults with type 2 diabetes. JAMA. 2016;315(10):1034-45.

58. Evans JM, Ogston SA, Emslie-Smith A, Morris AD. Risk of mortality and adverse cardiovascular outcomes in type 2 diabetes: a comparison of patients treated with sulfonylureas and metformin. Diabetologia. 2006;49(5):930-6.

59. Schramm TK, Gislason GH, Vaag A, et al. Mortality and cardiovascular risk associated with different insulin secretagogues compared with metformin in type 2 diabetes, with or without a previous myocardial infarction: a nationwide study. Eur Heart J. 2011;32(15):1900-8.

60. Ou SM, Shih CJ, Chao PW, et al. Effects on clinical outcomes of adding dipeptidyl peptidase- 4 inhibitors versus sulfonylureas to metformin therapy in patients with type 2 diabetes mellitus. Ann Intern Med. 2015;163(9):663-72.

61. Yu OH, Yin $\mathrm{H}$, Azoulay L. The combination of DPP-4 inhibitors versus sulfonylureas with metformin after failure of first-line treatment in the risk for major cardiovascular events and death. Can J Diabetes. 2015;39(5):383-9.

62. Scirica BM, Braunwald E, Raz I, et al. Heart failure, saxagliptin, and diabetes mellitus: observations from the SAVOR-TIMI 53 randomized trial. Circulation. 2014;130(18):1579-88.

63. White WB, Cannon CP, Heller SR, et al. Alogliptin after acute coronary syndrome in patients with type 2 diabetes. N Engl J Med. 2013;369(14):1327-35.

64. Zannad F, Cannon CP, Cushman WC, et al. Heart failure and mortality outcomes in patients with type 2 diabetes taking alogliptin versus placebo in EXAMINE: a multicentre, randomised, double-blind trial. Lancet. 2015;385(9982):2067-76.

65. Green JB, Bethel MA, Armstrong PW, et al. Effect of sitagliptin on cardiovascular outcomes in type 2 diabetes. N Engl J Med. 2015;373(3):232-42.

66. Fulcher G, Matthews DR, Perkovic V, et al. Efficacy and safety of canagliflozin used in conjunction with sulfonylurea in patients with type 2 diabetes mellitus: a randomized, controlled trial. Diabetes Ther. 2015;6(3):289-302.

67. Neal B, Perkovic V, de Zeeuw D, et al. Efficacy and safety of canagliflozin, an inhibitor of sodium-glucose cotransporter 2, when used in conjunction with insulin therapy in patients with type 2 diabetes. Diabetes Care. 2015;38(3):403-11.

68. Nissen SE, Wolski K. Effect of rosiglitazone on the risk of myocardial infarction and death from cardiovascular causes. N Engl J Med. 2007;356(24):2457-71.

69. Wilcox R, Bousser MG, Betteridge DJ, et al. Effects of pioglitazone in patients with type 2 diabetes with or without previous stroke: results from PROactive (PROspective pioglitAzone Clinical Trial In macroVascular Events 04). Stroke. 2007;38(3):865-73.

70. Dormandy JA, Charbonnel B, Eckland DJ, et al. Secondary prevention of macrovascular events in patients with type 2 diabetes in the PROactive Study (PROspective pioglitAzone Clinical Trial In macroVascular Events): a randomised controlled trial. Lancet. 2005;366(9493):1279-89.

71. Kernan $\mathrm{WN}$, Viscoli CM, Furie $\mathrm{KL}$, et al. Pioglitazone after ischemic stroke or transient ischemic attack. $\mathrm{N}$ Engl J Med. 2016;374(14):1321-31.

72. Zonszein $\mathrm{J}$, Lombardero $\mathrm{M}$, Ismail-Beigi $\mathrm{F}$, et al. Triglyceride high-density lipoprotein ratios predict glycemia-lowering in response to insulin sensitizing 
drugs in type 2 diabetes: a post hoc analysis of the BARI 2D. J Diabetes Res. 2015;2015:129891.

73. Wong HK, Ong KL, Cheung CL, Cheung BM. Utilization of glucose, blood pressure, and lipid lowering medications among people with type II diabetes in the United States, 1999-2010. Ann Epidemiol. 2014;24(7):516.e1-521.e1.

74. Huang ES, Karter AJ, Danielson KK, Warton EM, Ahmed AT. The association between the number of prescription medications and incident falls in a multi-ethnic population of adult type-2 diabetes patients: the diabetes and aging study. J Gen Intern Med. 2010;25(2):141-6.

75. UK Prospective Diabetes Study Group. Tight blood pressure control and risk of macrovascular and microvascular complications in type 2 diabetes: UKPDS 38. BMJ. 1998;317(7160):703-13.

76. Donnan PT, MacDonald TM, Morris AD. Adherence to prescribed oral hypoglycaemic medication in a population of patients with type 2 diabetes: a retrospective cohort study. Diabet Med. $2002 ; 19(4): 279-84$.

77. Blonde L, Wogen J, Kreilick C, Seymour AA. Greater reductions in $\mathrm{A} 1 \mathrm{C}$ in type 2 diabetic patients new to therapy with glyburide/metformin tablets as compared to glyburide co-administered with metformin. Diabetes Obes Metab. 2003;5(6):424-31.

78. Pan F, Chernew ME, Fendrick AM. Impact of fixed-dose combination drugs on adherence to prescription medications. J Gen Intern Med. 2008;23(5):611-4.

79. Thayer S, Arondekar B, Harley C, Darkow TE. Adherence to a fixed-dose combination of rosiglitazone/glimepiride in subjects switching from monotherapy or dual therapy with a thiazolidinedione and/or a sulfonylurea. Ann Pharmacother. 2010;44(5):791-9.

80. Cheong C, Barner JC, Lawson KA, Johnsrud MT. Patient adherence and reimbursement amount for antidiabetic fixed-dose combination products compared with dual therapy among Texas Medicaid recipients. Clin Ther. 2008;30(10):1893-907.
81. Melikian C, White TJ, Vanderplas A, Dezii CM, Chang E. Adherence to oral antidiabetic therapy in a managed care organization: a comparison of monotherapy, combination therapy, and fixed-dose combination therapy. Clin Ther. 2002;24(3):460-7.

82. Hutchins V, Zhang B, Fleurence RL, Krishnarajah G, Graham J. A systematic review of adherence, treatment satisfaction and costs, in fixed-dose combination regimens in type 2 diabetes. Curr Med Res Opin. 2011;27(6):1157-68.

83. Blonde L, San Juan ZT, Bolton P. Fixed-dose combination therapy in type 2 diabetes mellitus. Endocr Pract. 2014;20(12):1322-32.

84. Blonde L, San Juan ZT. Fixed-dose combinations for treatment of type 2 diabetes mellitus. Adv Ther. 2012;29(1):1-13.

85. Florez H, Luo J, Castillo-Florez S, et al. Impact of metformin-induced gastrointestinal symptoms on quality of life and adherence in patients with type 2 diabetes. Postgrad Med. 2010;122(2):112-20.

86. Hampp C, Borders-Hemphill V, Moeny DG, Wysowski DK. Use of antidiabetic drugs in the U.S., 2003-2012. Diabetes Care. 2014;37(5):1367-74.

87. Woo V. Empagliflozin/linagliptin single-tablet combination: first-in-class treatment option. Int J Clin Pract. 2015;69(12):1427-37.

88. Lewin A, DeFronzo RA, Patel $\mathrm{S}$, et al. Initial combination of empagliflozin and linagliptin in subjects with type 2 diabetes. Diabetes Care. 2015;38(3):394-402.

89. Rosenstock J, Inzucchi SE, Seufert J, Fleck PR, Wilson CA, Mekki Q. Initial combination therapy with alogliptin and pioglitazone in drug-naive patients with type 2 diabetes. Diabetes Care. 2010;33(11):2406-8.

90. Quilliam BJ, Simeone JC, Ozbay AB, Kogut SJ. The incidence and costs of hypoglycemia in type 2 diabetes. Am J Manag Care. 2011;17(10):673-80. 